\title{
GERENCIAMENTO DA INTEGRAÇÃO - ABORDAGEM DE CICLO DE VIDA ADAPTATIVO EM PROJETO DE CONSTRUÇÃO DE PLANTA SOLAR - RELATO DE EXPERIÊNCIA
}

\section{ARTIGO ORIGINAL}

MOREIRA JÚNIOR, Apparício Ramalho ${ }^{1}$

MOREIRA JÚNIOR, Apparício Ramalho. Gerenciamento da integração abordagem de ciclo de vida adaptativo em projeto de construção de planta solar - relato de experiência. Revista Científica Multidisciplinar Núcleo do Conhecimento. Ano. 06, Ed. 09, Vol. 01, pp. 58-92. Setembro 2021. ISSN: 24480959, Link de acesso: https://www.nucleodoconhecimento.com.br/engenhariamecanica/gerenciamento-da-integracao, DOI: 10.32749/nucleodoconhecimento.com.br/engenharia-mecanica/gerenciamento-daintegracao

\section{RESUMO}

O objetivo do presente relato de experiência foi apresentar as soluções utilizadas no Processo de Gerenciamento do projeto de Construção e Montagem de uma Planta Solar Fotovoltaica em Escala Utilitária, em contextos complexos, incertos e conflituosos. Como questão norteadora, pretende-se demonstrar que novas abordagens, adotadas no projeto aqui relatado - distintas do modelo e das práticas tradicionais - permitiram a mitigação dos principais problemas comuns aos projetos de construções, entre eles, as divergências entre projeto executivo e atividade em campo, os atrasos na entrega e prazos contratados inicialmente, e consequentes despesas adicionais ao orçamento base. Como metodologia, sua fundamentação teórica foi embasada em levantamento bibliográfico, abordando aspectos como:

\footnotetext{
${ }^{1}$ Pós-Graduação Lato Sensu - MBA em Gerenciamento de Projetos - Fundação Getúlio Vargas (FGV); Bacharel em Engenharia Mecânica - Universidade Federal de Pernambuco. ORCID: https://orcid.org/0000-0002-65069768
}

RC: 96261

Disponível em: https://www.nucleodoconhecimento.com.br/engenhariamecanica/gerenciamento-da-integracao 
gerenciamento de projetos e ciclo de vida dos mesmos, integração entre os diversos processos e partes interessadas (stakeholders), e a Energia Solar em escala utilitária, no âmbito da Construção. Tal relato de experiência visou discutir e demonstrar a abordagem utilizada no projeto Guañizuil II A, localizado na Argentina, no qual agilidade, flexibilidade e inovação resultaram além da mitigação de atrasos e de custos suplementares, à conquista de registros notáveis e ao desenvolvimento de alternativas práticas que podem ser aplicados a outros projetos de construção. Conclui-se que os projetos de engenharia, em sua fase executiva, precisam estar alinhados a realidade em campo, onde uma abordagem adaptativa pode trazer ganhos e impactos positivos em todo o ciclo de vida.

Palavras-Chave: Gerenciamento de Projetos, Construção e Montagem, Usinas Solares Fotovoltaicas, Ciclo de vida de Projetos, PMBOK®.

\section{INTRODUÇÃO}

É comum em boa parte da literatura relacionada aos projetos de engenharia a ideia de que "retrabalho, o atraso na entrega de obras e a extrapolação do orçamento" (SOUSA et al., 2020, p. 1), é um problema para a indústria da construção. Para conquistar a confiabilidade e segurança necessária para um projeto, Sousa et al. (2020, p. 2, referindo LEHTIRANTA, 2014) defendem que "o conjunto de procedimentos, critérios e diretrizes denomina-se Sistema de Gestão, cuja implementação deve ser pautada em uma estratégia clara".

De acordo com a experiência aqui relatada, aspectos como competitividade, qualidade e confiabilidade são tão fundamentais, que levam os diferentes profissionais ao máximo de cuidados durante toda a duração de um processo. Uma vez que tais aspectos interferem na aplicação de modelos genéricos de gerenciamento de projetos, e, considerando que o setor da Construção Civil requer "inúmeros serviços paralelos", destaca-se que todos os projetos desta área requerem planejamento, projeções, orçamento, cronograma, gerenciamento, execução e controle de qualidade. 
Dito de outra forma, diante de algumas particularidades nas diferentes obras, a gestão das mesmas leva à subdivisão de tais serviços em projetos menores, o que permite ao engenheiro gestor que tome as decisões mais pontuais para solucionar as questões que surgem durante a realização do projeto propriamente dito, decidindo de forma mais simples, e que estejam conformes ao escopo do sistema de gestão e ao gerenciamento como um todo (SOUSA et al., 2020).

É comum que entre os aspectos que caracterizam os projetos de Construção Civil sejam elencados "os atrasos, as perdas de materiais, a demora na tomada de decisão de proprietários e os erros de projeto" (TAFAZZOLI e SHRESTHA, 2017, p. 611). Tal estudo se refere especificamente às obras nos Estados Unidos; contudo, são questões confirmadas por outras fontes de pesquisa, assim como no empirismo que permeia as vivências da engenharia, requerendo, portanto, dos profissionais especializados, que identifiquem as melhorias a serem adotadas, que permitam a mitigação desses problemas.

Ainda na perspectiva desta experiência, o início da viabilização da implantação de um projeto solar em escala utilitária acontece mediante a prospecção de informações básicas de localização para que a incidência solar da região seja avaliada, e com isso, sua capacidade de geração de energia. A partir dessas informações, devem ser analisados também os insumos, mão de obra e equipamentos necessários para a instalação deste tipo de projeto, além da melhor estrutura financeira disponível para suportar tal empreendimento.

Além disso, são necessárias diversas informações que permitam a elaboração dos desenhos técnicos e a especificação dos materiais que definirão a forma de construção da unidade. Neste sentido devem ser utilizadas as informações produzidas em testes iniciais ou projetos similares, que permitam a verificação das condições do terreno, como por exemplo: a) resistência mecânica do solo para suportar as diversas cargas produzidas pelas estruturas mecânicas (trackers); b) força de arrancamento por conta do efeito do vento, efeito de temperatura sobre as estruturas; c) análise química do solo para verificar os efeitos da corrosão, entre 
outras informações que constam nos relatórios geológicos produzidos durante os estudos.

Já a etapa conhecida como Projeto Básico, do inglês: "Planning, Programming and Budgef', é, efetivamente, o início do projeto, e consiste, como o nome sugere, em: planejamento, programação e orçamento. A fase seguinte se refere ao detalhamento do Projeto de Execução, onde são aplicadas as boas práticas de engenharia em conjunto com a experiência, vivência e lições aprendidas em outros projetos.

São estabelecidas também as atividades complementares de logística quanto à disponibilidade dos materiais dos rastreadores (trackers), equipamentos de perfuração, bate-estacas (pile-driving machines), compra de painéis solares e de baterias, além da contratação de empreiteiros para terraplanagem, montagem, conexões elétricas e subestações, e ainda das atividades de apoio à obra, que precisam ser planejadas e executados pelo Gerente de Projetos, a partir de todos os dados executivos.

No que concerne aos projetos de energia renovável, inúmeras são as dificuldades a serem superadas para a geração deste tipo de energia. Entre as dificuldades na Construção, destacam-se as que podem ser agrupadas em três lacunas significativas: 1) Divergência de projeto; 2) Gestão ineficiente; 3) Escassez de força de trabalho experiente.

Tais lacunas, que serão detalhadas ao longo deste artigo, foram devidamente corrigidas por meio da aplicação de uma abordagem adaptativa no gerenciamento do projeto e na construtibilidade e montagem das estruturas durante a implantação do projeto de construção de um parque solar - em escala utilitária de 117MW projeto que foi denominado Guañizuil, 2A, e realizado durante o ano de 2019.

Uma vez que as inconsistências nos desenhos de construção surgem no projeto em campo, quando são consultados os estudos geológicos e as análises preliminares, e sobretudo, as necessidades técnicas para a montagem das estruturas (trackers), conjunto que pode ocasionar retrabalho, constatou-se que a efetivação do projeto 
em questão, situado na região da Cordilheira dos Andes, iria requerer uma abordagem específica, face aos riscos de fortes impactos e distorções, devido à altitude de sua localização.

Para mitigação das lacunas acima citadas, o conhecimento do Guia PMBOK® foram importantes, por meio das boas práticas para o gerenciamento de projeto neles contidas.

\section{GERENCIAMENTO DE PROJETOS APLICADO À CONSTRUÇÃO}

\subsection{GERENCIAMENTO DE PROJETOS}

O bom gerenciamento dos recursos disponíveis nas diferentes organizações tornouse, com o tempo, a peça fundamental para que as empresas possam ser mais competitivas e com isso progridam, o que implica em decisões pela adoção de várias ações a serem implementadas de forma consistente e constante.

Assim, cabe destacar de início que Siqueira; Menezes e Oliveira (2018, p. 2) referem Maximiano (2006, p. 363), para definir que projetos são:

Atividades temporárias, com começo, meio e fim programados, que têm como objetivo fornecer um produto singular. O resultado de um projeto pode ser um produto físico, como uma nova fábrica, um conceito, como um novo sistema de informações, ou um evento, como os jogos olímpicos. Muitos projetos são combinações desses três tipos de produtos.

Já Gomes et al. (2020, p. 107) defendem que os projetos se constituem em "evento único com prazo definido de início e fim”, Farias (2018, p. 13) explica que o conceito sobre sucesso em projetos foi se modificando, já que de início, os gestores avaliavam o sucesso na perspectiva técnica, e ainda da adequação ou falta de adequação do produto do projeto e do controle de custos.

Ainda Farias (2018) reporta ainda a definição elaborada por Vargas (2009, p. 14) sobre um projeto bem-sucedido, cabendo a este: "[...] ser concluído no prazo previsto, dentro do orçamento, atingindo a qualidade desejada, utilizando os 
recursos de forma eficiente, com o mínimo de alterações no escopo e ter sido aceito sem restrições pelo cliente".

O fato é que, em dado momento, ter sucesso em um projeto passou a representar, além dos demais aspectos, o cumprimento de prazos, o controle adequado dos custos e ainda, a oferta de algo em nível de qualidade compatível com o acordado desde o início. Esta era uma avaliação interna entre os gestores, existindo, contudo, um aspecto de grande relevância que ainda não era levado em conta: a satisfação do cliente (KERZNER, 2006, p. 40, apud FARIAS, 2018).

Por sua vez, Rabechini Jr. e Pessôa (2005, p. 34) ensinam que é somente por meio do desenvolvimento de "competências nos vários aspectos é que se pode desenvolver a maturidade em gerenciamento de projetos, uma vez que tal processo requer tempo e ainda se reflete em todos os setores da organização". Estes autores reportam Pinto (1983) e Sleven (1998) para explicar a existência de quatro critérios, em Gerenciamento de Projetos, a destacar: "tempo, custo, eficácia e satisfação do cliente".

São estes critérios que permitem que um projeto seja considerado bem-sucedido por especialistas, a partir de alguns fatores: missão, suporte gerencial, plano, cliente consultor, questões pessoais, questões técnicas, aceite cliente, comunicação, monitoramento e conciliação.

\subsection{GERENCIAMENTO DE PROJETOS NA CONSTRUÇÃO}

Sob a ótica deste relato, o segmento da Construção é um setor de produção para o qual a literatura criticava a falta de um manual a ser seguido. Cada projeto apresenta características específicas, que são inerentes ao valor do investimento, aos interesses e exigências de seus investidores, à localização para realização do projeto e suas especificidades locais, além das necessidades de pessoal especializado em cada etapa do projeto de engenharia.

RC: 96261

Disponível em: https://www.nucleodoconhecimento.com.br/engenhariamecanica/gerenciamento-da-integracao 
Na opinião de Sousa et al. (2020, p.1), o ramo da engenharia carece de "sistemas de gestão e de ferramentas e técnicas consolidadas para auxiliar na tomada de decisões", além de ainda faltarem regras e metas previamente definidas na elaboração de orçamentos e cronogramas.

Neste sentido, grande parte da literatura referia-se à carência de uma metodologia abrangente que ocasione resultados efetivos nas práticas da Construção Civil, que compreenda o projeto desde o início e até o seu final.

Xavier (2012, p. 1) destaca a definição sobre metodologia conferida por Charvat (2003):

uma metodologia é um conjunto de orientações e princípios que podem ser adaptados e aplicados em uma situação específica. Em ambiente de projetos essa orientação é uma lista de coisas a fazer. Uma metodologia pode também ter uma abordagem específica, modelos, formulários e também check lists, usados durante o ciclo de vida do projeto.

A este respeito, ainda Xavier (2012, p. 1) reporta que entre os resultados do "Estudo de Benchmarking em Gerenciamento de Projetos", de 2010, confirmou-se a carência de uma metodologia de gerenciamento de projetos nacional ou internacional, que seja eficaz e que possa ser utilizada de maneira geral pela área da Construção.

Tafazzoli e Shrestha (2017, p. 611), complementam as declarações de Xavier (2012) e de Souza et al. (2020), ao afirmarem que o atraso nos projetos de construção é um problema global, causando perdas consideráveis para muitas economias. Os autores apresentam uma pesquisa nacional realizada nos EUA, com especialistas experientes da indústria da construção, avaliando a criticidade relativa das causas de atraso. Verificou-se que devido às complexidades na padronização de projetos de construção, os esforços para mitigar os riscos de atraso não foram adequadamente bem-sucedidos.

Nesta perspectiva, o Guia PMBOK®, que é um guia de boas práticas, firmou-se ao longo do tempo como base para aplicação no Gerenciamento de Projetos nas diferentes áreas de mercado. Entretanto, como será visto de forma mais detalhada 
em subitem específico e sequencial a este, em dado momento foi necessária a criação de um guia menor, que contemplasse a indústria da Engenharia. Com esta iniciativa, o PMI permitiu aos gestores deste segmento que adotem boas práticas específicas, porém, com métodos internos, conforme a obra em realização.

\subsection{PROJECT MANAGEMENT INSTITUTE (PMI) E O GUIA PMBOK®}

O Project Management Institute (PMI), ou Instituto de Gerenciamento de Projetos foi criado em 1969, na Pensilvânia, Estados Unidos. Trata-se de uma instituição sem fins lucrativos, voltada às boas práticas no gerenciamento de projetos dos diferentes setores da economia (PMI, 2013).

A partir de um grupo de profissionais que integravam o PMI, foi criado em 1990 o Guia PMBOK®, obra desenvolvida para "orientar, padronizar e difundir as práticas mais eficientes em projetos em suas diferentes etapas, já testadas e aprovadas ao redor do mundo". Foi elaborado diante da evidente necessidade evidenciada da adoção de padrões para o bom gerenciamento de projetos, definindo a forma como o trabalho deve acontecer durante todo o ciclo de vida de um projeto.

Segundo Xavier (2012, p. 1), o Guia PMBOK® não traz uma metodologia de gerenciamento de projetos, mas sim que o "Guia aborda somente "o que" é necessário para o gerenciamento de projetos, sem entrar no mérito de "como" esses processos deveriam ser realizados e em que sequência". Face a eficácia obtida pelas empresas que adotam o PMBOK®, este foi reconhecido, em 1999, pelo American National Standards Institute (ANSI), como um padrão para o gerenciamento de projetos.

Com a finalidade de manter o Guia PMBOK® sempre atualizado, a cada quatro anos são elaboradas verificações condizentes com o momento atual da sociedade, quanto às novas necessidades e tecnologias.

Enquanto a 1ạ. edição do Guia PMBOK®, lançada em 1996 pelo PMI, trazia instruções para o aprimoramento da carreira em Gerenciamento de Projetos, em sua

RC: 96261

Disponível em: https://www.nucleodoconhecimento.com.br/engenhariamecanica/gerenciamento-da-integracao 
7ª. edição, atualizada em 2020, foram inseridas abordagens ágeis, adaptativas e híbridas (mistura das tradicionais com as ágeis), aplicáveis em possíveis contextos e cenários dos diferentes projetos.

Por sua vez, a crescente demanda dos agentes das diversas indústrias levou os especialistas do PMI à elaboração e publicação de diversas extensões ou guias específicos, para melhor direcionar os gestores das diferentes áreas.

No tocante à indústria da Construção, elaborou-se em 2003 a 1a. versão do manual Construction Extension to the PMBOK® Guide, ou Extensão do Guia PMBOK® para a Construção, que contempla as necessidades deste setor.

Fornecendo orientação aplicável especificamente aos projetos de Construção, o Construction Extension To The PMBOK® Guide oferece - aos profissionais do Gerenciamento de Projetos - orientações e diretrizes sobre áreas adicionais não encontradas no Guia base, conforme descrevem os artigos de Best (2021), e os da CBIC (2020 e 2021), a destacar:

- Recursos: compreende os recursos humanos, os técnicos, e ainda os recursos em equipamentos, materiais e serviços;

- Integridade, Segurança e proteção do projeto e gerenciamento ambiental: traz uma abordagem protetiva direcionada ao ambiente do canteiro de obras;

- Gerenciamento Ambiental: aborda a questão da localização do projeto, tendo em vista existir uma forte influência em projetos de construção, como as questões que envolvem o solo e o clima, aspectos que afetam diretamente o escopo, o cronograma e os recursos destinados ao projeto. $\mathrm{O}$ isolamento do projeto relativamente aos centros urbanos impacta a infraestrutura e a logística do mesmo;

- Gerenciamento financeiro do projeto: Aborda os recursos para o financiamento da Construção, incluindo desde a obtenção do 
financiamento e seu gerenciamento, assim como o faturamento e o monitoramento do fluxo de caixa;

- Reinvindicações (pleitos): trata das contestações e disputas entre as partes interessadas, quanto às mudanças de escopo, cronograma e riscos, entre outros.

Também são interessantes as referências dedicadas ao Gerenciamento do Ciclo de Vida e Custo do Ciclo de Vida, bem como todos os aspectos relacionados ao meio ambiente e responsabilidade social.

A 1a. edição do Extensão do Guia PMBOK® para a Construção foi publicada em 2002, enquanto a última atualização foi em 2016. Essa última edição mantém a mesma estrutura que o Guia base, contendo prefácio, capítulos introdutórios, áreas de conhecimento, anexos e apêndices, além de seguir a organização das áreas de conhecimento e o esquema dos grupos de processos de iniciação, planejamento, execução, monitoramento e controle, e encerramento.

Uma vez que se trata de um material direcionado para a indústria da Construção, essa Extensão do Guia PMBOK® (2016, p. 20) apresenta os diferentes tipos de projetos inerentes a esta área, como demonstradas na tabela 1. 
Tabela 1 - Mapeamento de grupos de processos e áreas de conhecimento

\begin{tabular}{|c|c|c|c|c|c|}
\hline \multirow[b]{2}{*}{ Áreas de Conhecimento } & \multicolumn{5}{|c|}{ Grupos de Processos em Gerenciamento de Projetos } \\
\hline & $\begin{array}{l}\text { Grupo de } \\
\text { Processo } \\
\text { de } \\
\text { Iniciação }\end{array}$ & $\begin{array}{c}\text { Grupo de } \\
\text { Processo } \\
\text { de } \\
\text { Planejamento }\end{array}$ & $\begin{array}{c}\text { Grupo de } \\
\text { Processo } \\
\text { de } \\
\text { Execução }\end{array}$ & $\begin{array}{l}\text { Grupo de } \\
\text { Processo de } \\
\text { Monitoramento } \\
\text { ou Controle }\end{array}$ & $\begin{array}{l}\text { Grupo de } \\
\text { Processo de } \\
\text { Fechamento }\end{array}$ \\
\hline $\begin{array}{l}\text { 4. Gerenciamento de Integração em } \\
\text { Projetos }\end{array}$ & 濭 & in & 湮 & $\mathbf{1}$ & $\mathbf{n}$ \\
\hline 5. Gerenciamento de Escopo em Projetos & & $\mathbf{E}$ & & $\mathbf{E}$ & \\
\hline $\begin{array}{l}\text { 6. Gerenciamento de Cronograma em } \\
\text { Projetos }\end{array}$ & & 垔 & & 圆 & \\
\hline 7. Gerenciamento de Custo em Projetos & & 重 & & 垔 & \\
\hline $\begin{array}{l}\text { 8. Gerenciamento de Qualidade em } \\
\text { Projetos }\end{array}$ & & 䙵 & 睘 & 曋 & \\
\hline $\begin{array}{l}\text { 9. Gerenciamento de Recursos em } \\
\text { Projetos }\end{array}$ & & 圆 & $\mathbf{E}$ & - & - \\
\hline $\begin{array}{l}\text { 10. Gerenciamento de comunicação em } \\
\text { Projetos }\end{array}$ & & $\mathbf{m}$ & 畺 & 瞏 & \\
\hline 11. Gerenciamento de Risco em Projetos & & $\mathbf{E}$ & & 圆 & \\
\hline $\begin{array}{l}\text { 12. Gerenciamento de Aquisições em } \\
\text { Projetos }\end{array}$ & & 鲤 & $\mathbf{E}$ & : & $\mathbf{m}$ \\
\hline $\begin{array}{l}\text { 13. Gerenciamento de Partes Interessadas } \\
\text { em Projetos }\end{array}$ & $\mathbf{n}$ & 표 & $\mathbf{n}$ & 要 & \\
\hline $\begin{array}{l}\text { 14. Gerenciamento de Saúde, segurança } \\
\text { seguridade e ambiental em Projetos }\end{array}$ & & - & - & - & \\
\hline $\begin{array}{l}\text { 15. Gerenciamento Financeiro em } \\
\text { Projetos }\end{array}$ & & - & & - & \\
\hline
\end{tabular}

Fonte: Tradução do autor, com base no PMI (2016, p.20).

\subsection{AS BOAS PRÁTICAS EM CONSTRUÇÃO SEGUNDO A EXTENSÃO DO GUIA PMBOK®}

Dados da Câmara Brasileira da Indústria da Construção (CBIC) demonstram que o setor de Construção foi responsável por $3,4 \%$ do Produto Interno Bruto (PIB) brasileiro ao longo de 2020, proporcionando emprego a 2,269 milhões de trabalhadores.

Este segmento ocasionou a criação de 45.249 novas posições de trabalho, número esse que consiste na diferença entre 152.553 admissões e 107.304 demissões. Dito de outra forma, foram gerados pela Construção acima de "100 mil empregos formais até setembro de 2020, de acordo com os dados apresentados pelo novo CAGED, e 
divulgados pela Secretaria Especial de Previdência e Trabalho do Ministério da Economia “(CBIC, 2020b).

Nos Estados Unidos da América, país sede do Project Manager Institute - PMI, a indústria da construção participa com 4,3\% do PIB e emprega 11,8 milhões de trabalhadores (CBIC) (2020b).

De início, cabe destacar que o tamanho da indústria da Construção justifica o fato de - PMI ter desenvolvido um guia específico, contendo as boas práticas voltadas a este setor. O impacto da indústria da Construção e sua fundamental importância na economia de diferentes países justifica a criação - por parte do PMI - de um guia de boas práticas específico para este setor, ação que enriqueceu o Guia PMBOK®, diante da publicação da Extensão do Guia PMBOK® para a Construção, dedicado a pormenorizar conceitos e práticas de sucesso.

De acordo com a Extensão, as seções de 1 a 3 descrevem a estrutura e as características específicas que são exclusivas de projetos de Construção, seus ciclos de vida de projetos. Por sua vez, as seções de 4 a 13 correspondem às dez Áreas de Conhecimento descritas no Guia PMBOK®, apresentando adições ou modificações, descrevendo atributos específicos para a indústria da Construção, além de enfatizar aquelas atividades e práticas que são de importância única neste setor (PMI, 2016).

Em um segmento tão importante, a adoção de um gerenciamento estratégico de obras possibilita obter resultados positivos (BEST, 2021). No entanto, tudo isso começa muito antes do primeiro movimento no local de construção - já que a mudança deve ter início nos projetos; por isso, os conceitos do PMBOK® e as boas práticas de Construção tratadas na Extensão do Guia abordam temas característicos, que serão descritos a partir desta etapa do presente artigo, com base no mesmo.

1. Público-alvo especializado da indústria da Construção: há uma quantidade significativa de Partes Interessadas em um projeto de Construção, 
principalmente em obras de grande complexidade e de elevados recursos financeiros (PMI, 2006, p. 4).

Os principais, porém não limitados a eles, são: Gerentes de construção, gerentes de projeto, Empreiteiros, Subempreiteiros, estimadores, programadores, engenheiros de custos, analistas de controle de projetos, Arquitetos, projetistas, engenheiros; Especialistas em gestão de risco, Especialistas em geotécnica e materiais perigosos, Agências reguladoras e governos, Organizações não-governamentais (ONGs) e empresas privadas; Grupos ambientais, Grupos comunitários, Prospectivos proprietários de casas, Incorporadores imobiliários, Vendedores e fornecedores de materiais e equipamentos de construção, especialistas em logística e transporte, Consultores e advogados de construção, Seguradoras, bancos e instituições financeiras. Em síntese, aqui estão todas as Partes Interessadas no processo de construção, desde a aquisição do terreno até o projeto, construção e ocupação.

\section{A estrutura organizacional dos projetos de Construção - Projeto,} Programa e Portifólio: segundo a Extensão do Guia PMBOK® para Construção, o papel e o tamanho de uma organização determinam, frequentemente, se ela administrará seus projetos dentro de portfólios ou programas. A classificação e definição do porte dos projetos gerenciados cabe à organização - entre pequenos, médios e grandes - e desta forma, como tais projetos devem seguir dentro da estrutura corporativa, ou seja, se serão tratados como programas ou como projetos dentro da organização (PMI, 2016, p. 5).

3. O papel do escritório de projetos PMO na indústria de Construção: Dentro de um projeto de Construção existe o foco em manter a consistência na gestão e na execução dos projetos. Alguns projetos podem ser referidos como melhores práticas, em complementação às práticas comuns de PMO.

Segundo a Extensão do Guia PMI (2016, p. 6-7), as práticas especialmente importantes para a indústria da Construção podem ser: 
1) o registro histórico de projetos para utilização em estimativa de custos e licitação; 2) práticas em processos de Saúde Ocupacional, segurança, proteção e gestão ambiental; 3) procedimentos de garantia de qualidade e inspeção de terceiros para controle de qualidade; 4) práticas em administração de contratos; 5) práticas em administração de subempreiteiros, vendedores e fornecedores; 6 ) melhores práticas na gestão de reivindicações, gestão de pedidos e reclamações.

4. O papel do Gerente de Projetos de Construção: há características bem especificas na indústria de Construção, sendo possível que existam gerentes de projetos atuando com as Partes Interessadas em uma única obra/projeto. Quer esta posição resida com o contratante (vendedor de serviços) ou com o proprietário (comprador dos serviços), o gerente do projeto deve ter conhecimento, experiência e competência para compreender e definir as interrelações entre o projeto e os componentes de gerenciamento do projeto.

Segundo a Extensão do Guia, o papel do gerente do projeto em Construção requer conhecimentos especializados, pois as questões relativas à administração são as principais causas de problemas em um projeto desta indústria (PMI, 2016, p. 7).

5. Partes Públicas Interessadas: segundo a Extensão do Guia, a indústria da Construção trabalha frequentemente sob o escrutínio do público, consumindo, essencialmente, receitas advindas dos contribuintes; desta forma, a crítica ou interferência pública podem afetar direta ou indiretamente o projeto (PMI, 2016, p. 8).

6. Outras normas: muitos projetos estão submetidos ao cumprimento de normais e códigos ou legislação governamental (PMI, 2016, p. 8).

\subsection{AMBIENTE DE CONSTRUÇÃO E OS IMPACTOS DOS FATORES EXTERNOS}

O guia traz luz a uma característica importante dos projetos executados nesta indústria, que consiste na relevância da localização do projeto. Considerações sobre a geografia local, a infraestrutura já existente, população local e distância de centros urbanos, entre outras, são características que podem influenciar o tempo, os custos 
e os métodos de construção/instalação dos projetos. Até mesmo a financiabilidade do empreendimento pode ser impactada pelo ambiente e pelo local da construção (PMI, 2016).

Cabe também destacar aqui que não apenas os fatores internos e diretamente ligados aos projetos de Construção são capazes de influenciar e interferir no gerenciamento dos projetos deste segmento, mas também os fatores ambientais que são, em sua predominância, externos. A Extensão do Guia (PMI, 2016, p. 9), ao explicar que os principais fatores que "influenciam os resultados do projeto de construção, por exemplo, apresenta os aspectos econômicos, financeiros e de localização do local".

Um outro aspecto relevante considerado na Extensão do Guia (PMl, 2016, p. 13) se refere à localização do ambiente, devido aos fortes impactos possíveis sobre o projeto. A questão geográfica pode levar a custos mais dispendiosos durante o período de construção, em se tratando de região com solos distintos, os quais poderão requerer adaptações só descobertas quando as etapas de construção forem iniciadas.

Ainda no que se refere à localização do projeto a ser realizado, estão as possíveis necessidades de treinamento de mão de obra local, o que deverá ser feito do início das atividades, quando se tratar de obras em regiões que não possuam a infraestrutura necessária para suportar o volume de mão de obra durante a construção. Por fim, e não menos importante, está a questão da logística para a chegada de materiais ou equipamentos, já que poderão surgir necessidades quanto à adaptação ou ainda da construção de condições e local de acondicionamento deles.

\subsection{MÉTODOS DE ENTREGA DE PROJETOS}

O Método de Entrega de um projeto de Construção depende do ambiente do projeto, sendo sua escolha influenciada por fatores como: tipo e tamanho da construção; 
legislação federal e estadual; atividade do proprietário; nível de conhecimento e experiencia; especialização e tempo dedicado ao projeto. $O$ método também impactará diretamente a estratégia para contratação de equipamentos, ferramentas, materiais e serviços (PMI, 2016, p. 10).

A Extensão do Guia PMBOK® de Construção (2016) apresenta alguns métodos utilizados como melhores práticas, sendo os mais comuns: Projeto-construçãoelaboração; Projeto - construção; Enginnering, Procurement e Construction (EPC) ou Engenharia, aquisição e construção; Autodesempenho; Integrated Project Delivery (IPD) ou Entrega de projeto integrado e Parceria público-privada (PPP).

Em grandes projetos, principalmente no caso das grandes obras, o método de entrega mais utilizado pela indústria de Construção é o Engenharia, Aquisição e Construção (EPC). A utilização desse método de entrega ocorre - principalmente pela busca da mitigação do risco da contratante, uma vez que se trata de um contrato de empreitada global em que a contratada - que normalmente é uma empreiteira com capacidade técnica e financeira robusta.

Em casos como esse, uma empreiteira de porte costuma assumir a obrigação de realizar o projeto de engenharia, executar todas as atividades inerentes ao seu escopo, fornecer - por fontes próprias ou de terceiros - todos os materiais e equipamentos necessários ao empreendimento, e ainda, instalar, montar, testar e comissionar esses equipamentos, de forma que a obra seja concluída em um prazo determinado, e entregue à operação.

Há variações na abrangência do escopo da contratada em efetuar ou não algumas etapas especificas como, por exemplo, testes e comissionamento.

Em projetos complexos é possível que se verifique a existência de estruturas que contam com diversos contratos com escopos complementares, ou seja, quando existem contratos separados para tecnologia, engenharia básica e de detalhamento, construção civil, montagem, gerenciamento, entre outros. Cada um desses contratos engloba os serviços EPC correspondentes à sua área.

RC: 96261

Disponível em: https://www.nucleodoconhecimento.com.br/engenhariamecanica/gerenciamento-da-integracao 
Nos casos em que uma das Partes Interessadas é constituída por agentes públicos através de governos ou órgão públicos, o método de entrega normalmente utilizado é a Parceria Público-Privada (PPP). No universo das PPPs, os métodos típicos de entrega de projetos incluem concessões, Build, Operate and Transfer (BOT) ou construir, operar e transferir, e Design Build Operate Mantain (DBOM) ou projetar, construir, operar e manter.

\subsection{CICLOS DE VIDA DOS PROJETOS DE CONSTRUÇÃO}

Todas as informações para o começo de um projeto são frágeis. Dessa forma, no início da fase de execução, surgem problemas que devem ser corrigidos, para o sucesso da obra. Nesta perspectiva, e de acordo com as orientações das boas práticas da Extensão do Guia PMBOK® de Construção (2016), a maioria desses projetos tem um ciclo de vida que consiste na concepção, projeto, construção, comissionamento e fechamento, embora esta indústria adote, usualmente, a reformulação de algumas dessas fases.

Na prática, a indústria de Construção subdivide todo o processo em mais fases, sendo que cada uma delas corresponde à perspectiva da parte interessada, sob o ponto de vista do proprietário dos projetos. Como exemplo, pode-se mencionar fases como Desenvolvimento, para a qual, as informações iniciais do projeto prospectadas fazem sentido, diferentemente da perspectiva de um empreiteiro.

Neste sentido, Molwus (2014, p.58) explica que:

As principais decisões (propostas e projeto executivo) relativos ao projeto são efetuados na fase de preparação do investimento, que é seguido pela fase de execução do projeto, durante o qual os trabalhos são realizados no local, de modo a realizar os objetivos do projeto, com base nas decisões e escolhas feitas durante o projeto executivo. Após a fase de execução é a fase de operação, onde se espera que benefícios do projeto sejam extraídos (tradução livre).

Uma das características da indústria da Construção é que muitos aspectos dos projetos são estabelecidos no início do Ciclo de Vida do Projeto, quando há maior 
incerteza; nessa fase, alguns escopos contratuais são firmados e mudanças contratuais são um desafio adicional.

A contratação de empreiteiros no início do Ciclo de Vida do Projeto pode ser eficaz em termos de tempo, mas o grau de Desenvolvimento de Informações sobre o projeto poderá afetar o custo e as alternativas de consuntibilidade e contratação. Consta, na Extensão do Guia PMBOK® para a Construção, que "os contratos, que são redigidos e acordados durante o período de maior incerteza, devem incluir disposições para uma distribuição justa e apropriada dos riscos associados a questões emergentes" (PMI, 2016, p. 17).

Essa é uma boa prática, que visa dividir o risco entre contratante e contratada, mas ainda assim, não elimina custos futuros, dadas as indefinições iniciais do projeto. Uma vez que empresas contratadas podem emitir orçamentos e taxas de preço com base em determinada quantidade de material, carga horária de recursos de equipamentos em quantidade menor do que a necessária, evidencia-se uma situação que vai requerer um reequilíbrio contratual.

Em projetos que requeiram altos investimentos é comum serem utilizados para seus processos, os Ciclos de Vida Preditivos, visando reduzir riscos e maximizar a probabilidade de sucesso; são do tipo de processos com limite de tempo, conhecidos como Front-End Loading (FEL) ou Planejamento de Pré-Projeto, que se refere à realização de um planejamento e projeto sólido em estágios iniciais (ou Front-End do projeto).

O processo FEL inclui momentos de decisão (geralmente três: FEL1, FEL2 e FEL3) em marcos bem definidos, quando é tomada a decisão de que a próxima etapa será efetuada.

A Extensão do Guia PMBOK® para a Construção fornece uma visão geral das informações que, normalmente, são desenvolvidas antes de cada porta de fase; contudo, a organização executa seus marcos, de acordo com seus recursos e objetivos (PMI, 2016, p. 17).

RC: 96261

Disponível em: https://www.nucleodoconhecimento.com.br/engenhariamecanica/gerenciamento-da-integracao 
Tabela 2 - Entregáveis do portal de estágio FEL

\begin{tabular}{|c|c|c|}
\hline FEL 1 & FEL 2 & FEL 3 \\
\hline $\begin{array}{l}\text {-Objetivos de performace } \\
\text { - Avaliação das alternativas } \\
\text { tecnológicas } \\
\text {-Estudos de viabilidade } \\
\text { - Cronograma de marcos } \\
\text { - Investimento estimado } \\
\text { (+- 50\%), Estimativa de } \\
\text { despesas operacionais } \\
\text { (+-100\%) }\end{array}$ & $\begin{array}{l}\text {-Engenharia conceitual e } \\
\text { Básica } \\
\text {-Avaliação técnica } \\
\text { - Cronograma Conceitual } \\
\text { - Orçamento estimado } \\
\text { (+-30\%) } \\
\text { - Identificação de itens } \\
\text { financiáveis }\end{array}$ & $\begin{array}{l}\text { - Projeto de engenharia } \\
\text { ( FEED) ( desenhos técnicos, } \\
\text { fluxogramas) } \\
\text { - Plano preliminar de compras } \\
\text { e aquisições. } \\
\text {-Escopo do trabalho } \\
\text { - Cronograma de recursos } \\
\text {-Orçamento definitivo } \\
\text { (+10\%) }\end{array}$ \\
\hline
\end{tabular}

Fonte: Tradução do autor, com base no PMI (2016, p.17).

Em geral, ao utilizar os conceitos de Front-End Loading (FEL) em projetos de Construção, o risco do projeto é reduzido e os proprietários têm uma quantidade maior de informações estratégicas, levando a um projeto mais relacionado às decisões comerciais. A aplicação do FEL permite aos membros da equipe pensarem em todos os subsistemas e fatores de impacto.

Ciclos de Vida Adaptativos, também conhecidos como métodos ágeis ou orientados para a mudança, destinam-se a facilitar essa mudança, exigindo um alto grau de envolvimento contínuo das Partes Interessadas. Os métodos adaptativos são geralmente preferidos quando se trata de um ambiente em rápida mudança, quando as exigências e o escopo são difíceis de definir antecipadamente. Por sua vez, quando é possível definir pequenos melhoramentos incrementais, estes proporcionarão valor às Partes Interessadas.

Projetos de construção são, por natureza, uma atividade determinista, mais complexos e resistentes em adotar Ciclos de Vida Adaptativos. Em grandes projetos, a aquisição de equipamentos críticos costuma ser efetuada com meses de antecedência às suas efetivas aplicações no canteiro de obras. Quando surgem diferenças entre as versões dos dados emitidos no projeto básico e os dados após a 
aquisição de materiais e equipamentos, torna-se uma situação que pode gerar impacto nas versões anteriores, reduzindo o espaço para adaptações ou mudanças.

A depender do objetivo do projeto, o Ciclo de Vida Adaptativo pode ser substituído por um modelo concorrente, no qual as fases podem se sobrepor, ou seja, deve-se adotar o modelo de Ciclos de Vida Interativos.

Como exemplo, pode-se mencionar que nas adaptações de processos construtivos definidos durante o projeto básico, ocorram alterações no projeto de detalhamento e o replanejamento dessa atividade, que pode ser feito de forma interativa, através de uma série de ciclos repetidos, à medida que o projeto avança.

A este respeito, Molwus (2014, p. 58) defende que "em diferentes fases do projeto haverá partes interessadas entrando e saindo, bem como se interrelacionando com elementos do projeto ou outras partes interessadas".

\subsection{GERENCIAMENTO DE INTEGRAÇÃO DE PARTES INTERESSADAS (STAKEHOLDERS)}

Por definição, as Partes Interessadas consistem no grupo de pessoas envolvidas em um projeto de Construção. Segundo a Extensão do Guia PMBOK® para a Construção (2016, p. 135), existem os participantes diretos envolvidos com determinado projeto, são eles: "participantes de projetos, proprietários do projeto, arquitetos ou engenheiros projetistas, empreiteiros, subempreiteiros e fornecedores de materiais".

Por sua vez, os participantes indiretos de um projeto de Construção se constituem de um grupo assim composto (PMI, 2016, p. 135):

agências ou autoridades reguladoras (isto é, em relação à segurança, saúde ocupacional e meio ambiente). questões); Associações profissionais; Público em geral, incluindo residentes locais, grupos; Proprietários de terras e pessoas afetadas por projetos; Sindicatos de trabalhadores; Departamentos do governo local; Mídia; lobistas ou grupos de peticionários; outros empreendimentos de construção que possam afetar o projeto;

RC: 96261

Disponível em: https://www.nucleodoconhecimento.com.br/engenhariamecanica/gerenciamento-da-integracao 
Representantes e associações nacionais da indústria ou de empresas; e Polícia e outros serviços de emergência.

Outro aspecto importante a destacar, no que tange às Partes Interessadas reside no fato de que, de acordo com a localização geográfica e especificidades de determinados projetos de construção, podem existir outras Partes Interessadas entrantes em tal projeto. Dito de outra forma, tanto os participantes diretos quanto os indiretos não se limitam apenas aos acima mencionados.

Entre todas essas etapas, Da Rosa e Esteves (2016, p. 13) destacam a Gestão da Integração das Partes Interessadas ou Stakeholders, normatizadas no Brasil segundo a NBR ISO 21500, de 2012, conforme a Associação Brasileira de Normas Técnicas (ABNT). Os autores explicam que, para que um projeto seja concluído, é necessário que exista harmonia entre todas as partes que o integram. Equivale a dizer que clientes, gestores, e demais participantes estejam de acordo e satisfeitos, como demonstra a figura 3 .

Figura 3 - Identificando os Stakeholders 


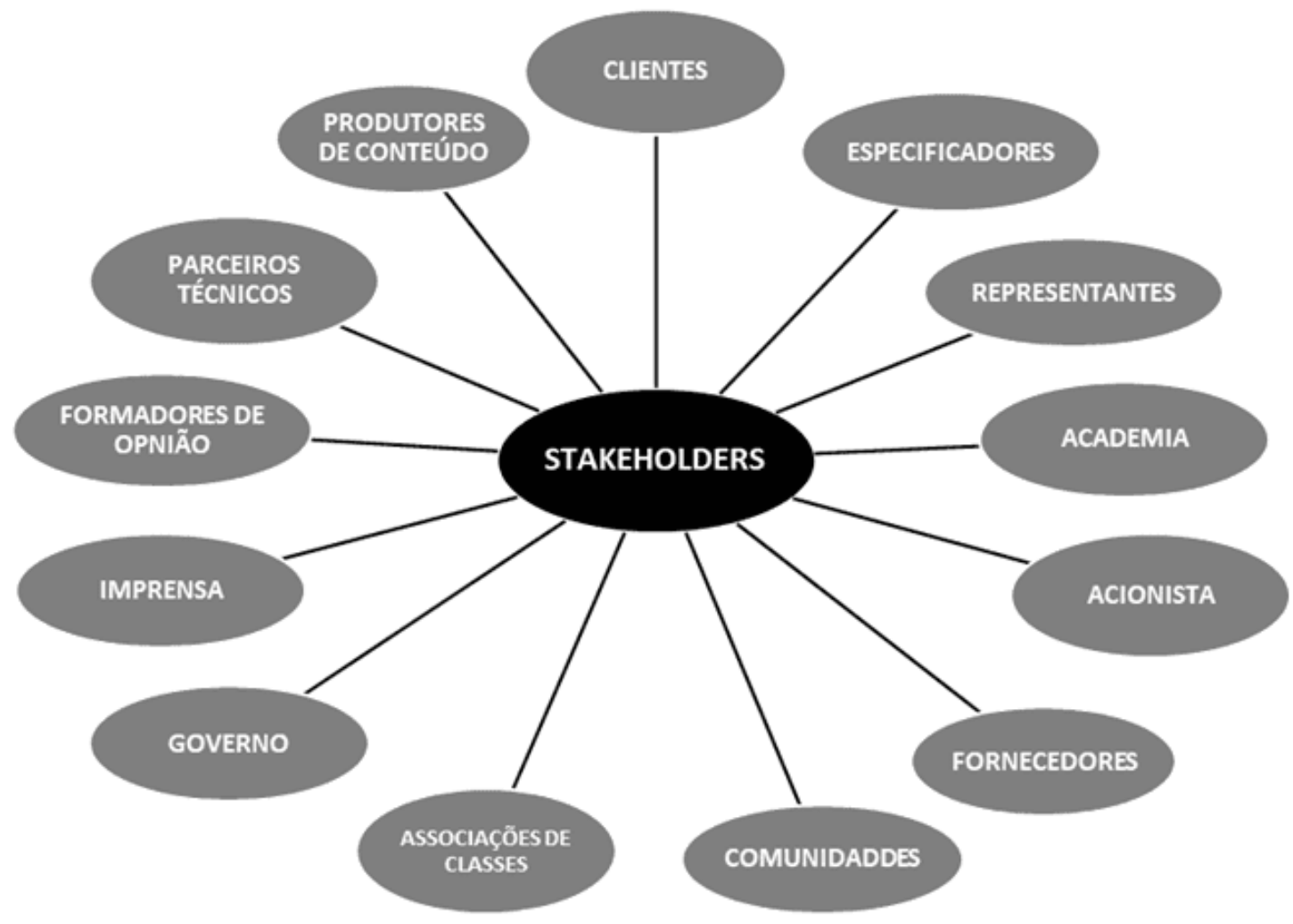

Fonte: Elaboração do autor, com base no Portal Fixe (2012).

Siqueira; Menezes e Oliveira (2018, p. 4-5) defendem que o próprio Guia PMBOK® (2013) define que "o Gerenciamento das Partes Interessadas do projeto inclui os processos exigidos para identificar todas as pessoas, grupos ou organizações que podem impactar ou serem impactados pelo projeto". Porém, o PMBOK® ressalta também que "todos os envolvidos em um projeto devem ser inseridos, e não apenas aqueles que detém o poder financeiro ou de comando sobre as decisões e estratégias a serem seguidas".

A despeito da ressalva do $\mathrm{PMBOK} \circledast$, Siqueira et al. $(2018$, p. 5) referem Robbins (2005, p. 302) para defender que "uma pessoa só pode ter poder sobre você se ela controlar algo que você deseja". Neste sentido, Siqueira et al. (2018, p. 5) evidenciam a importância das relações, expectativas, inclinações e níveis de influência do poder exercido dos stakeholders, relativamente aos demais envolvidos, 
diante de decisões e do "[...] direcionamento estratégico do projeto de acordo com o grupo envolvido e com o grau de poder de cada stakeholder".

Estes autores apresentam ainda a definição de stakeholders, defendida por Xavier (2006, apud SIQUERA et al., 2018, p. 5):

Gerente de projetos: a pessoa responsável pelo gerenciamento do projeto;

Cliente: a pessoa ou organização que irá utilizar o produto ou serviço do projeto;

Membros da equipe: as pessoas que compõem a equipe do projeto;

Organização executora: a empresa em que o projeto está sendo executado;

Patrocinador (sponsor): a pessoa ou o grupo, dentro ou fora da organização executora, que provê recursos financeiros e/ou apoio institucional para a execução do projeto.

Para Montes (2020), o guia PMBOK® visa a criação de estratégias que envolvam todas as partes envolvidas - stakeholders - quebrando suas resistências em questões/momentos em que discordem umas das outras.

Ao concordar com as definições dadas por Xavier (2006), Montes (2020) ainda as reforça: existem clientes relativos à Gerência de Projeto, responsável pelo planejamento, envolvimento das partes e por todas as ações e etapas do projeto, na direção de seus objetivos.

\subsection{ENERGIA SOLAR EM ESCALA UTILITÁRIA EM CONSTRUÇÃO}

\subsubsection{MATRIZES ENERGÉTICAS}

Segundo Inatomi e Udaeta (2005), foi a partir da Revolução Industrial que os recursos naturais passaram a ser explorados de forma muito rápida e intensa, sem cuidados ou preocupações quanto às tecnologias desenvolvidas e possíveis prejuízos sociais e ao meio ambiente, ocasionando os enormes impactos ambientais já conhecidos no presente. Estes autores referem os impactos gerados no meio 
ambiente - sem considerar a finitude dos recursos naturais - pela humanidade abrangem 0 setor energético de forma dinâmica, afetado por motivos socioeconômicos, implicando em respostas das dimensões social, econômica, política e ambiental (INATOMI e UDAETA, 2005, p. 190)

Destacam também que, em uma perspectiva global, estima-se o consumo de " $80 \%$ da energia consumida advém da queima de combustíveis fósseis (carvão, petróleo e gás natural)" (COSTA, 2005, apud INATOMI e UDAETA, 2005, p. 191).

\subsubsection{ENERGIA SOLAR}

As energias renováveis "são qualquer meio de energia oriundo de fontes biológicas, geofísicas ou solares, os quais se recompõem a uma velocidade igual ou superior ao seu consumo", conforme descreve o relatório do Painel Integrado sobre Mudanças Climáticas da ONU (SERVOS, 2016, p. 12). Segundo a Agência Nacional de Energia Elétrica (ANEEL) (2002), "radiação solar pode ser usada como fonte para geração de energia térmica, elétrica e potência mecânica".

De acordo com Daros (2013, p. 15), a radiação solar é convertida em energia elétrica a partir de efeitos de contato "termoelétrico e fotovoltaico". Enquanto o aproveitamento passivo da energia solar proporciona calor e iluminação, o aproveitamento térmico se dá por meio de coletores ou concentradores solares, ocasionando o aquecimento de fluidos em edificações domésticas, por exemplo. Já no que se refere à "geração de energia elétrica, ela se dá pelos efeitos da radiação (calor e luz) sobre determinados materiais" [...]" ou seja, "o efeito fotovoltaico, que decorre da excitação dos elétrons de alguns materiais na presença da luz solar" (ANEEL, 2005, apud DAROS, 2013, p. 15).

A energia solar pode produzir eletricidade quando em contato com as placas fotovoltaicas, já que são compostas por várias placas de silício, cujos elétrons "são energizados ao contato com a luz solar", o que permite a geração de eletricidade para construções residenciais ou comerciais. Ao contrário das outras formas de 
geração de eletricidade, o sistema "fotovoltaico é obtido de forma direta e produz com isso corrente elétrica, que é processada por dispositivos controladores e conversores, que são armazenadas em baterias ou utilizada diretamente em sistemas conectados à rede elétrica" (VILLALVA, 2015, apud PINA e CORRÊA, 2018, p.17).

\subsubsection{INSTALAÇÃO DE UM PARQUE SOLAR}

Face ao crescimento populacional mundial, e com 0 avanço das diferentes tecnologias e setores, na busca por fontes alternativas de energias renováveis e sua adoção, está a energia fotovoltaica. Entretanto, de custo elevado para grande parte da população de consumidores, surgiram "os condomínios solares, que ao mesmo tempo, produziriam energia para vários consumidores, barateando o equipamento, por se tratar de uma compra em grande escala" (PINA e CORRÊA, 2018, p. 14).

Segundo Guarnieri (2017, p.40), as principais etapas de desenvolvimento de um projeto solar são:

Primeiro contato, ideia inicial e descrição geral do projeto;

Avaliação do site - aspectos técnicos e legais: verificação prévia do ponto de conexão; adequação do terreno adequado à instalação em região com bom índice de irradiação solar; estudo da geração solar preliminar;

Desenvolvimento do projeto básico preliminar: consulta do acesso à rede; análise de investimento; contrato de compra/aluguel do terreno; estudo ambiental e obtenção do Licenciamento Prévio; medição de dados ambientais e certificação da produção de energia;

Cadastramento da usina para habilitação (em caso de participações em leilões federais);

Projeto básico: orçamento dos principais componentes; Construção; custos administrativos e O\&M; avaliação econômica para acerto de preço da energia negociada;

Leilão de energia: PPA - Contrato de compra de energia; Contratos da SPE;

Fonte garantida de recurso para implantação (financiamentos ou investimentos privados); 
Viabilização do ponto de conexão;

Negociação com principais fornecedores: solicitação de propostas; roteiro para avaliação das propostas técnicas e econômicas;

Levantamento de custo e alternativas de implantação;

Projeto executivo: consolidação das especificações dos equipamentos e materiais; elaboração de desenhos de projetos e listas de compras; cronograma da construção;

Aquisição de materiais;

Construção: preparação do site e mobilização; atividades de caráter civil e montagem eletromecânica; testes de operação: testes elétricos, comissionamento;

Inauguração.

As atividades construtivas de um parque solar estão muito interligadas às necessidades específicas dos equipamentos a serem instalados. Entre as etapas da obra de uma UFV, Guarnieri (2017, p.48) detalha a etapa inicial do processo construtivo em si:

Etapa de obra civil: inicia com o processo de supressão vegetal, confirmação da topografia e terraplanagem quando necessário, construção de acessos internos e posterior confecção das valas de drenagem e de encaminhamento de cabos;

Etapa de montagem mecânica: é composta pela instalação das fundações, posterior montagem das traves e mesas de suporte e finalmente a fixação dos módulos fotovoltaicos;

Montagem elétrica: quando as conexões dos módulos são efetivadas e ocorre o encaminhamento dos cabos de baixa tensão até as caixas de junção e inversores. Nos eletrocentros ocorre a elevação da tensão e então os circuitos de média tensão são encaminhados para a subestação de concessão da usina. Todos os elementos são também devidamente protegidos através de instalação de um adequado sistema de aterramento e proteção.

Comissionamento: antes da conexão e início da operação da usina, os elementos componentes da usina são inspecionados visualmente e através de testes mecânicos e elétricos, certificando o projeto e os parâmetros previstos de operação. 
Conforme descrito por Pinho e Galdino (2014, p. 144), os componentes básicos de um sistema fotovoltaico são: módulos solares, baterias, inversores, estruturas metálicas, cabos elétricos e subestação. Cada um dos itens relacionados possui suas características e necessidades particulares para instalação e funcionamento, remetendo à etapa seguinte, que é a de integração de todas as diferentes funcionalidades, etapas de fabricação, transporte e instalação no local do projeto de construção do parque solar.

Entre os itens básicos estão as estruturas metálicas, que são os equipamentos para suportar os módulos solares, podendo ser estruturas fixas ou que têm a funcionalidade de seguir a posição solar, também chamados de trackers ou rastreadores solares.

A fim definir uma configuração otimizada para o projeto, quanto à montagem das estruturas metálicas, devem ser realizados estudos e análises de diversas informações, como por exemplo um estudo geológico do solo, a partir de um pull out tests, para levantamento de informações de resistência do solo, contemplando:

Ensaios de identificação e classificação dos solos: os ensaios mais relevantes consistem na análise mineralógica, análise granulométrica, determinação do Wnat (Umidade Natural do Solo), dos pesos volúmicos e dos limites de Atterberg;

Ensaio de Standard Penetration Test (SPT): tem como objetivo determinar, em profundidade, a resistência dos solos à penetração dinâmica;

Ensaio de DPSH: subdivide-se em DPSH-A e DPSH-B, conforme a altura de queda do martelo ser de $0,5 \mathrm{~m}$ ou de $0,75 \mathrm{~m}$, respectivamente, sendo a massa do martelo de $63,5 \mathrm{~kg}$. O DPSH alcança profundidades superiores a $25 \mathrm{~m}$, sendo o registo do número de golpes efetuado para que ocorra a cravação da ponteira cónica de $10 \mathrm{~cm}$ (N10) ou de $20 \mathrm{~cm}$ (N20).

A associação entre os ensaios é frequente nas atividades de caracterização geotécnica de áreas com alguma dimensão, permitindo combinar uma malha mais 
alargada de ensaios SPT com outra mais apertada de ensaios DPSH, mais rápidos e económicos de serem executados, resultando numa caracterização mais completa do terreno.

Não é foco desse relato de experiência detalhar cada etapa dos testes realizados, mas tê-los como referência, a fim de contextualizar a criticidade em projetos de construção de informações dos documentos de projetos. Os resultados apresentados nos diversos relatórios servem de parâmetros para identificar limites aceitáveis para os esforços a serem suportados pelo solo, dimensionamento de estruturas e definição de alternativas construtivas a serem aplicadas no campo.

Com as informações oriundas dos testes, pode-se planejar as demais etapas de construção do empreendimento. Os testes geológicos vão interferir fortemente na etapa de construção civil e de montagem mecânica, relatadas abaixo.

\subsection{RELATO DE EXPERIÊNCIA}

É consenso na literatura que os projetos de engenharia civil - a nível mundial costumam atrasar, e com isso, apresentar novas projeções financeiras para sua concretização, podendo ter seu custo final aumentado.

A este respeito, Xavier (2012, p. 3) refere que os artigos científicos baseados em pesquisa de campo demonstram que o problema reside no não cumprimento dos prazos, embora o gerenciamento de prazos seja o foco principal de todo projeto. Este autor explica ainda que, na prática, os atrasos são consequências de diferentes fatores, como os problemas com fornecedores, ou os riscos não avaliados corretamente, entre outros.

Neste sentido, o que se quer demonstrar é a importância de serem consideradas e integradas consistentemente as nove (9) áreas de conhecimento propostas pelo Guia PMBOK® (PMI, 2008): "escopo, tempo, custo, qualidade, recursos humanos, comunicações, risco, aquisições e integração". 
Ocorre que para que seja possível a realização e concretização de um projeto na Indústria da Construção, além das responsabilidades inerentes à Gestão de Projetos, estão as mudanças ocorridas ao longo do tempo.

Sob essa ótica, Sousa et al. (2020, p. 13) ensinam que quanto mais a Gestão de Projetos se consolidou, a importância dada ao Gerente de Projetos foi se destacando sensivelmente. Ao Gerente de Projetos cabe absorver as seguintes mudanças, ocorridas ao longo do tempo:

- Uma pessoa sozinha tem a responsabilidade total pelo projeto;

- Funcionários dedicam-se a projetos e não a funções;

- Coordenação única entre as interfaces funcionais;

- O planejamento e controle integrados utilizados adequadamente.

O presente Relato baseia-se na experiência realizada durante a construção e montagem de uma Usina Solar em Escala Utilitária na província de San Juan, Argentina. O início da implantação do projeto ocorreu em 2018, sendo que as etapas finais de atividade civil de terraplanagem para iniciar a montagem das estruturas ocorreu em janeiro 2019.

O grupo de Engenharia Mecânica foi assim composto: um gerente de engenharia mecânica - bacharel em engenharia mecânica e com forte experiência em gerenciamento de projetos e na implantação de projetos solares; três engenheiros mecânicos com experiência em outras indústrias.

O projeto contou com uma área de engenharia corporativa da proprietária do projeto e responsável pelos projetos executivos, como também o suporte do departamento de engenharia do fabricante de trackers, localizado no estado da Califórnia, USA.

O método de entrega do projeto utilizado foi por contrato de Engineering, Procurement and Construction (EPC), o que, segundo a Extensão do Guia PMBOK® de Construção (2016, p.10-11), é o método de entrega proeminente na indústria da Construção.

RC: 96261

Disponível em: https://www.nucleodoconhecimento.com.br/engenhariamecanica/gerenciamento-da-integracao 


\subsubsection{A ABORDAGEM GERENCIAL}

Uma vez que é no momento da execução do projeto em campo que ficam evidentes os dados inconsistentes nos desenhos de construção, desenvolvidos na etapa anterior, ao chegar no empreendimento, é usual que o profissional envolvido no gerenciamento de projeto de construção consulte os documentos até então elaborados, para tomar conhecimento das informações levantadas durante os estudos e análises realizadas e utilizados para o desenvolvimento de outros documentos de engenharia. São consultados os estudos geológicos, os documentos de fornecedores de equipamentos, no caso em referência foi dada atenção as necessidades técnicas a serem atendidas para a montagem das estruturas (trackers).

Nesse contexto, foram identificadas as interações que envolveram as disciplinas de engenharia civil e engenharia mecânica, no tocante às atividades de nivelamento do terreno para cumprir com tolerâncias de nível e declividade.

Alguns fornecedores possuem diferentes configurações de equipamentos para permitir a montagem em diferentes condições de terrenos.

A diferença de cotas em diferentes pontos do terreno impacta na altura livre versus engastamento necessários para garantir a resistência da estrutura aos esforços provenientes de vento.

Nessa etapa de análise de informações, no respectivo projeto, foram identificados problemas em levantamentos de topografia utilizados para o nivelamento do terreno. A localização do projeto, próxima à região dos Andes, apresentava aspectos específicos que interferem diretamente nas especificações técnicas.

Em janeiro de 2019, o cronograma do projeto estava sob enorme pressão, uma vez que vários caminhos críticos apontavam para uma extensão no tempo para a conclusão da etapa de montagem das estruturas mecânicas, devido à inconsistência de dados geológicos, que impactaria negativamente todo o cronograma,

RC: 96261

Disponível em: https://www.nucleodoconhecimento.com.br/engenhariamecanica/gerenciamento-da-integracao 
ocasionando custos adicionais. Evidenciava-se a necessidade de respostas rápidas para mitigar a divergência no cronograma base.

O Ciclo de vida do projeto relatado seguiu, basicamente, as boas práticas da indústria de Construção, consistindo na concepção, projeto básico, projeto executivo, construção, comissionamento, integração à rede, e operação e manutenção. Seguindo o padrão dos projetos de construção, muitos aspectos foram estabelecidos no início o Ciclo de Vida do projeto quando a incerteza é maior; desta forma, foi necessária uma adaptação no replanejamento de atividades e a inclusão de etapa adicional com verificação "on-site" de todos os desenhos executivos, e realização de testes geológicos e técnicos.

Em um processo determinista caberia à equipe de campo reportar as inconsistências, e aguardar novos documentos com as adequações no processo e os impactos em todas as fases, inclusive nas datas. Contudo, suportada pela experiência técnica dos profissionais em campo e, contando com a habilidade no gerenciamento de projetos dos mais experientes, optou-se por seguir o caminho de realização de estudos e análises de diversas informações descritos anteriormente no próprio local da obra, ou seja, "on-site".

As inclusões das atividades de verificação no local da obra, os documentos envolvidos na elaboração dos desenhos a serem utilizados durante a construção, bem como a realização de testes, foi a decisão acertada para otimizar o processo, ao invés de retroceder o projeto para a etapa anterior de engenharia, com o objetivo de replanejar as datas de construção.

Nesse momento foi tomada a decisão de aplicar um modelo de Ciclo de Vida Adaptativo ao projeto, onde etapas iriam se sobrepor e se ajustar à medida que a obra avançaria.

Segundo Oliveira (1995), podemos entender como construtibilidade a habilidade ou facilidade deste em ser construído. Esse conceito amplia-se, de modo a alinhar a 
experiência técnica às premissas do projeto, através do pleno conhecimento da tecnologia construtiva a ser adotada no empreendimento.

De acordo com a Extensão do Guia PMBOK® de Construção (2016, p. 06):

Quando acoplada à velocidade com que a informação é distribuída e as decisões são tomadas, um ambiente de projeto de alta complexidade e demanda é criado. Para apoiar este ambiente, espera-se que o gerente do projeto de construção seja adaptável e, em alguns casos, possua uma ampla base de conhecimento em avanços na construção, tais como tecnologia e contratação alternativa de métodos de entrega.

Também foi estabelecido um plano de monitoramento e controle das Partes Interessadas, específico para este conjunto de atividades. Foi implementado um sistema de gerenciamento do fluxo de comunicação e aprovação das mudanças com as áreas de engenharia de projetos corporativos, com os fornecedores das estruturas e com os empreiteiros.

Com um workflow eficiente de distribuição dos resultados dos testes, foram realizadas adequações dos desenhos de projetos e orientações empreiteiros, suportado por curtos encontros diários, que envolveram grupos específicos de interessados para compreender e resolver pontos de inconsistências e implantação de soluções. Também foi estabelecida uma forte parceria com o fornecedor das estruturas mecânicas (trackers).

Todas essas iniciativas resultaram em uma dinâmica eficaz para a gestão da obra, assim como para as adaptações necessárias na construtibilidade e montagem das estruturas.

A este respeito, Tafazzoli e Shrestha (2017, p. 619) apresentam em seu estudo, soluções para evitar as principais causas de atrasos em projetos de construção, entre elas, recomendam que seja garantida a colaboração entre as partes ao longo de todo o projeto, por meio da realização de reuniões constantes. Isto permite a tomada de decisão integrada e o planejamento sobre como alcançar os resultados, considerando as integrações entre as tarefas.

RC: 96261

Disponível em: https://www.nucleodoconhecimento.com.br/engenhariamecanica/gerenciamento-da-integracao 


\subsubsection{A SOLUÇÃO TÉCNICA}

O empreendimento em questão localizava-se próximo à Cordilheira dos Andes, requerendo uma abordagem diferenciada da utilizada em locais que se encontram mais próximos do nível do mar. As curvas de topografia utilizadas como base de referência sofrem fortes impactos e distorções, devido à altitude de sua localização.

O procedimento ideal a ser adotado deve utilizar curvas de topografia específicas para esses locais ou, a depender do caso, elaborar-se o cálculo de um fator de correção para os dados localmente levantados durante a etapa de topografia do terreno.

Esse problema interfere nas etapas de nivelamento do terreno, com a identificação de pontos de corte e aterro, assim como no planejamento de distribuição de pontos de cravação das estacas metálicas, determinando sua altura livre do solo (e a respectiva profundidade de cravação), além da distância entre elas.

Uma vez que os trackers possuem diferentes tolerâncias de instalação, que são mínimas, o que se constitui em um detalhe que requer uma atenção especial. Para melhor exemplificar, podem ser mencionados:

- Inclinação das estacas;

- Torção da estaca sobre seu próprio eixo;

- Altura livre e profundidade mínima de cravação a serem respeitadas;

- Distância entre estacas;

- Respeito aos diferentes tipos de estacas utilizadas, devido à diferença entre os trackers dentro de uma mesma área (externo ou interno, por exemplo);

- Tolerâncias de montagem dos demais componentes, tubos de torque/torção, suportes, inclinação e alinhamento entre eles etc.

Caso ocorra alguma inconsistência nas etapas iniciais, as tolerâncias permitidas nas fases seguintes podem não ser suficientes para absorver os erros consecutivos de montagem.

RC: 96261

Disponível em: https://www.nucleodoconhecimento.com.br/engenhariamecanica/gerenciamento-da-integracao 
Esse projeto teve como premissas que os trackers suportassem a ação de ventos de até $115 \mathrm{~km} / \mathrm{h}$, devido à existência do vento Zonda, muito comum na região de implantação, e temperaturas de operação de até $10^{\circ}$ graus centígrados negativos.

Tais condições são bem difíceis para a operação de um parque solar, uma vez que, ao se concluir a montagem de painéis solares sobre um tracker, a estrutura deve suportar a carga de compressão e de esforços laterais produzidos pelo vento. As variações de temperatura muito rápidas também e impactam no funcionamento dos acoplamentos e suportes, os quais devem absorver adequadamente os esforços gerados pela dilatação térmica dos diversos componentes.

Durante as análises realizadas em campo, contemplando os dados geológicos e necessidades de terreno para a montagem dos trackers, foi identificada a necessidade de levantamentos adicionais de topografia do terreno, a fim de identificar diferenças existentes, assim como identificar problemas no posicionamento dos pontos onde seriam instaladas as estacas, a fim de cumprir com o distanciamento entre elas, como também as alturas livres do solo.

Constatou-se como problema inicial a existência de uma diferença de $+20 \mathrm{~cm}$ entre as cotas planejadas, e as efetivamente executadas em campo. Isso acarretou a necessidade de busca de alternativas técnicas que propiciassem um melhor aproveitamento das estacas que ficaram sem cumprir com as alturas especificadas em projeto.

Esse levantamento propiciou ajustes no processo de nivelamento do terreno, ajustes no plano de estaqueamento, também conhecido com ramming plan, e correções antecipadas de áreas com alturas acima do permitido para o projeto. Como as estacas caracterizavam uma malha mais fechada, $7 \mathrm{~m} \times 7 \mathrm{~m}$, enquanto a malha utilizada para o nivelamento do terreno considerava uma de $20 \mathrm{~m} \times 20 \mathrm{~m}$.

A etapa seguinte das análises levou ao desenvolvimento de critérios de cravação, levando-se em conta o tipo de terreno e os testes de cravação realizados no início 
do projeto. Assim, foi estabelecido um critério de tempo limite de 6 minutos para o processo de estaqueamento, e plano inicial de produção.

Outro critério definido foi o limite mínimo de engastamento / cravação das estacas no solo, e consequente altura livre, que permitisse o alinhamento e a montagem dos demais componentes do tracker. Alguns fabricantes permitem que sejam realizados cortes nas estacas, a fim de regularizar sua altura e aproveitamento para montagem dos demais componentes; contudo, existem critérios limites para esse aproveitamento.

Há de se levar em consideração os furos existentes para a montagem dos suportes e suas distâncias para as bordas das estacas. Essas distâncias são calculadas para permitir uma resistência mecânica para os elementos de fixação e da própria estrutura. Não se pode reduzir nem aumentar em demasiado essas distâncias, a fim de não impactar na resistência final da estrutura.

As análises dos dados permitiram implantar no projeto três diferentes alternativas de cravação das estacas, diretamente no solo, com pré-furo e uso de concreto. Essas alternativas, alinhadas ao critério de seleção por resultado de pull out tests, levaram a um maior aproveitamento das cravações realizadas.

Face às incertezas durante o processo de cravação, a presença de pequenas rochas nas diversas camadas do terreno provocou um número considerável de estacas que não cumpriram com os requisitos do projeto, seja pela altura ou pelo deslocamento no final do processo de cravação, provocando deslocamentos e inclinações indesejadas.

A realização de testes com cravação de estacas diretamente no solo, com levantamento de tempo de produção, números de estacas que não cumpriram com os parâmetros do projeto, e busca de alternativas que reduzissem os custos na realização dessa atividade, propiciou ao projeto a sua conclusão dentro dos prazos estabelecidos, com registros de pontos de correção por parte do fornecedor do 
tracker, de poucos pontos a serem corrigidos ou esclarecidos, para manter a garantia dos equipamentos por período superior a 25 anos.

Os resultados obtidos com a abordagem descrita também possibilitaram 0 replanejamento na etapa subsequente de montagem de painéis solares, aplicando o processo de compressão de atividade (crashing), através de um esforço concentrado de montagem em um período específico e bem curto.

A execução ficou a cargo do empreiteiro da região, devido à sua expertise para contratação de mão de obra local e fornecimento de equipamentos para a realização das atividades; contudo, sob gestão direta da proprietária do projeto.

Essa concentração de esforço foi bem-sucedida, permitindo a instalação de mais de 54.000 painéis, em um período de 12 horas, com registro de recorde mundial no período avaliado.

\section{CONSIDERAÇÕES FINAIS}

De acordo com todas as teorias descritas ao longo deste artigo, assim como das ações adotadas para a efetivação do projeto em questão, observa-se que os resultados alcançados foram importantes, tendo em vista que a etapa que antes apontava para um caminho crítico das atividades que reforçava os riscos no cronograma e custos no projeto foram mitigados.

Para essa etapa, e utilizando como referência os valores estimados de projetos base padrão, podemos relatar que os custos totalizaram aproximadamente USD $22,780,000.00$, sendo que $20 \%$ desse valor são relativos a custos diretos com serviços de execução da instalação e montagem dos trakers e módulos.

Com a abordagem desenvolvida e as estratégias implementadas, o impacto econômico foi positivo. Considerando as referências padrão antes mencionadas, o ganho econômico foi na ordem de $4 \%$ dos custos totais, decorrente diretamente da 
recuperação do tempo de montagem das estruturas em 04 semanas, como também uma reação nas demais etapas subsequentes em 06 semanas.

Com a ação do desafio de montagem de módulos, conseguiu-se produzir um quantitativo de estruturas e módulos instalados e prontos para adiantar as etapas de interligação elétrica dos módulos (seriado), lançamento de cabos das redes de Baixa Tensão (BT), interligação de inversores na versão String, dentre outras etapas construtivas.

Pode-se afirmar que com a aplicação de estratégias diferenciadas, o projeto conquistou ganhos, que vão além de uma disciplina ou atividade específica. Essa aplicação diferenciada impactou no desempenho das demais áreas, como Civil e Elétrica do projeto, bem como em todas as etapas subsequente da cadeia.

O resultado acima foi possível, tendo em vista a abordagem técnica utilizada, realizando alterações no projeto inicial e aplicando métodos que deram produtividade ao processo. Como exemplo, pode-se mencionar a adoção de processos construtivos, por meio do qual imprimiu-se velocidade no cravamento de estacas para suportar as estruturas que apoiam os módulos solares.

Com a o desafio da montagem mecânica das estruturas vencida, foi possível adotar uma abordagem direcionada a gestão de esforços concentrados da etapa subsequente de instalação dos módulos solares, aplicando o processo de compressão, que demandou um assertivo gerenciamento de recursos sendo máquinas, equipamentos e pessoas em quantidade superior ao planejado a esta fase do projeto.

Ao analisar os ajustes nos processos construtivos, e na busca da redução do tempo de deslocamento de pessoas, materiais, ferramentas e equipamentos nas áreas de construção, verificou-se também maior ganho de tempo na execução do trabalho como um todo, permitindo um avanço maior nas etapas da obra. 
Observa-se também que, melhorar a comunicação e a coordenação entre as partes interessadas foi essencial para mitigar os riscos do cronograma.

Conclui-se que a aplicação das boas práticas em gerenciamento de projetos de construção, aliada à experiencia em campo de um forte corpo de conhecimento técnico, aliado a expertise em gerenciamento de projetos, foram imprescindíveis para aplicar com sucesso um modelo de Ciclo de Vida Adaptativo, onde atividades e fases foram sobrepostas de modo planejado e eficiente, uma vez que a adaptação e replanejamento do processos definidos durante a fase do projeto básico e de detalhamento para montagem dos trackes e instalação dos módulos, fossem alterados durante a fase de execução de modo interativo, à medida que o projeto avançava. Isso em um projeto de construção, cuja natureza determinista e o grande número de partes interessadas tornam o desafio mais complexo.

\section{REFERÊNCIAS}

BEST, Raynor de. PIB e empregos da indústria de construção nos EUA. $\begin{array}{llllll}\text { Publicado em } & 27 & \text { abr } & 2021 . & \text { Disponível }\end{array}$ [https://www.statista.com/statistics/192049/value-added-by-us-construction-as-apercentage-of-gdp-since-]; acesso em 08/03/2021.

CBIC - CÂMARA BRASILEIRA DA INDÚSTRIA DA CONSTRUÇÃO. Resumo dos principais indicadores do setor da Construção Civil. Sala de imprensa. Artigo publicado em 05 mai 2021. Disponível em: [http://www.cbicdados.com.br/menu/salade-imprensa/sala-de-imprensa]; acesso em 08/03/2021.

. Participação (\%) do PIB da Construção Civil no PIB Total Brasil - 2000 a 2020. Publicado em 2020a. Disponível em: [http://www.cbicdados.com.br/media/anexos/1.3.1_Sala_de_Imprensa_22.pdf]; acesso em 08/03/2021.

- Construção Civil gerou mais de 100 mil empregos formais até setembro. Matéria publicada em 29 out 2020b. Disponível em: 
[https://cbic.org.br/construcao-civil-gerou-mais-de-100-mil-empregos-formais-atesetembro/\#: :text=Construção\%20Civil\%20gerou\%20mais\%20de\%20100\%20mil\%2 0empregos\%20formais\%20até\%20setembro,-

Em\%20setembro\%2C\%20a\&text=Desse\%20total\%2C\%205\%2C93\%25,\%2C43\%25 \%20(45.249); acesso em 08/03/2021.

DAROS, Higor Brusch. Integração de fontes de Energia Renováveis. Monografia [Graduação] em Engenharia Elétrica, apresentada à Universidade Federal do Rio Grande do Sul. PA, 2013. Disponível em: [https://lume.ufrgs.br/bitstream/handle/10183/96208/000915410.pdf?sequence=1\&is Allowed=y]; acesso em 08/03/2021.

FARIAS, Raileide Amaral de. O gerenciamento da integração como fator de sucesso no Gerenciamento de Projetos Dissertação MBA [Pós-graduação lato sensu] em Gerenciamento de Projetos, apresentada à Fundação Getúlio Vargas (FGV). Salvador (BA). Março de 2018. Disponível em: [https://www15.fgv.br/network/tcchandler.axd?tccid=7839]; acesso em 08/03/2021.

GOMES, Letícia Fernandes Bella; FREITAS, Karine Fátima de; BELLA, Ricardo Luiz Fernandes; DEL-VECCHIO, Renata Raposo; LIMA, Gilson Brito Alves. Centralidade de grafos aplicada à projetos de Energia Renovável. Mix Sustentável. Florianópolis, vol.6, n.4, p.105-114, ago. 2020. Disponível em: [https://redib.org/Record/oai_articulo2788443-centralidade-de-grafos-aplicada-àprojetos-de-energia-renovável]; acesso em 08/03/2021.

GUARNIERI, Mauricio Vivan. Usinas solares fotovoltaicas com seguimento em um eixo no Brasil: aspectos da construção, custos e expectativa de desempenho. Dissertação [Mestrado] em Engenharia Civil, Área de concentração Construção Civil, da Universidade Federal de Santa Catarina. Florianópolis, 2017. Disponível em: [http://fotovoltaica.ufsc.br/Dissertacoes/Dissertacao_Mauricio_Vivan_Guarnieri.pdf]; acesso em 08/03/2021. 
INATOMI, Thais Aya Hassan Inatomi; UDAETA, Miguel Edgar. Análise dos Impactos Ambientais na produção de energia dentro do Planejamento Integrado de Recursos. 2005.2 Disponível em: [https://www.academia.edu/36538516/ANÁLISE_DOS_IMPACTOS_AMBIENTAIS_N A_PRODUÇÃO_DE_ENERGIA_DENTRO_DO_PLANEJAMENTO_INTEGRADO_D E_RECURSOS]; acesso em 08/03/2021.

MOLWUS, Jurbe Joseph. Stakeholder Management in Construction Projects: A Life Cycle Based Framework. PhD thesis in Construction Philosophy, presented to Heriot Watt University. Oct, 2014. Available in: [https://core.ac.uk/download/pdf/77035943.pdf]; access in march 8, 2021.

MONTES, Eduardo. Gerenciamento das partes interessadas: o que é e como fazer. 02 out 2020. Disponível em: https://escritoriodeprojetos.com.br/gerenciamento-das-partes-interessadas-doprojeto; acesso em 01/03/2021.

OLIVEIRA, Ricardo Rocha. Sistematização e a listagem de fatores que afetam a construtibilidade. [In]: Encontro Nacional de Engenharia de Produção - ENEGEP, 1995.

PINA, Jorge Henrique de Morais; CORRÊA, Victor Japiassú. Implementação De Usinas Fotovoltaicas Com Geração Compartilhada. Monografia [graduação] apresentada ao Curso de Engenharia Civil da Unievangélica. ANÁPOLIS, 2018. Disponível em: [http://repositorio.aee.edu.br/handle/aee/114]; acesso em 08/03/2021.

PINHO, João Tavares; GALDINO, Marco Antonio. Manual de engenharia para sistemas fotovoltaicos. 2014. CEPEL/CRESESB. Disponível em: [http://www.cresesb.cepel.br/publicacoes/download/Manual_de_Engenharia_FV_201 4.pdf]; acesso em 08/03/2021. 
PMI-SP - PROJECT MANAGEMENT INSTITUTE São Paulo, Brasil. Certificação PMISP. 2020. Disponível em: [https://pmisp.org.br/pmi-sp/]; acesso em 08/03/2021.

PMI - PROJECT MANAGEMENT INSTITUTE. Um Guia do Conhecimento de Gerenciamento de Projetos. Guia PMBOK. 6를ição. 2017.

. INC. Constrution Extension to the PMBOK® Guide. Pensilvania, USA. 2016.

. Um Guia do Conhecimento de Gerenciamento de Projetos. Guia PMBOK. 5a. edição. 2013.

. Um Guia do Conhecimento de Gerenciamento de Projetos. Guia PMBOK. 4를 Edição. 2012

RABECHINI JR, Roque; PESSÔA, Marcelo Schneck de Paula. Um modelo estruturado de competências e maturidade em gerenciamento de projetos. Revista Produção, vol. 15, n. 1, p. 034-043, Jan./Abr. 2005. Disponível em: [https://www.scielo.br/pdf/prod/v15n1/n1a03.pdf]; acesso em em 08/03/2021.

SERVOS, Frederico Madeira De Ley. Os Estímulos Dos Usuários de Sistemas Fotovoltaicos Do Rio De Janeiro. Monografia [Graduação] em Administração de empresas apresentada ao Departamento de Administração do CENTRO DE CIÊNCIAS SOCIAIS (CCS) da Pontifícia Universidade Católica (PUC) do Rio de Janeiro. Rio de Janeiro, Dezembro de 2016. Disponível em: [https://www.maxwell.vrac.puc-rio.br/31009/31009.PDF]; acesso em 08/03/2021.

SIQUEIRA, Vera Aparecida Cordeiro; MENEZES, Bruno Anthony Gonçalves; OLIVEIRA, Altamir Fernandes de. Gerenciamento das Partes Interessadas: diagnóstico realizado com base no PMBOK® na Pró-Reitoria de Extensão e Cultura da UFVJM. Anais do VII SINGEP - São Paulo - SP - Brasil - 22 e 23/10/2018. Disponível em: [http://www.singep.org.br/7singep/resultado/179.pdf]; acesso em 08/03/2021.

RC: 96261

Disponível em: https://www.nucleodoconhecimento.com.br/engenhariamecanica/gerenciamento-da-integracao 
SOUSA, Rodrigo Zanata Pereira de; BARBOSA, Fernanda Azevedo; CALDEIRA, Michael Vinícius Martins; STIVAL, Ângela Mendes. Gestão de projetos aplicada à construção civil. Revista Científica Multidisciplinar Núcleo do Conhecimento. Ano 05, Ed. 01, Vol. 01, pp. 14-30. Janeiro de 2020. ISSN: 2448-0959. Disponível em: [https://www.nucleodoconhecimento.com.br/engenharia-civil/gestao-de-projetos]; acesso em: 08/03/2021.

TAFAZZOLI, Mohammadsoroush; SHRESTHA, Pramen P. Investigating Causes of Delay in U.S. Construction Projects. 53rd ASC Annual International Conference Proceedings. Sept $2017 . \quad$ Disponível em: [https://www.researchgate.net/publication/326693706]; acesso em 08/03/2021.

XAVIER, Carlos Magno da S. Metodologia de Gerenciamento de Projetos. Beware Consultoria Empresarial Ltda. 2012. Disponível em: [http://g2b.com.br/downloads/07_metodologia_gerenciamento_de_projetos_carlos_ magno_da_silva_xavier_2012.pdf]; acesso em 08/03/2021.

Enviado: Junho, 2021.

Aprovado: Setembro, 2021. 